\title{
Risk factors for chronic thromboembolic
}

\section{pulmonary hypertension}

\author{
D. Bonderman*, H. Wilkens" ${ }^{\#}$, S. Wakounig ${ }^{\star}$, H-J. Schäfers ${ }^{+}$, P. Jansa ${ }^{\S}$, J. Lindner ${ }^{f}$, \\ I. Simkova**, A.M. Martischnig*, J. Dudczak*, R. Sadushi*, N. Skoro-Sajer*, \\ W. Klepetko ${ }^{\# \#}$ and I.M. Lang*
}

ABSTRACT: Chronic thromboembolic pulmonary hypertension (CTEPH) is characterised by nonresolving pulmonary thromboemboli that can be treated by surgical pulmonary endarterectomy (PEA). The authors of the present study sought to confirm known and to identify novel CTEPH risk factors in a controlled retrospective cohort study of prevalent CTEPH cases collected in three European centres offering PEA.

Data from CTEPH patients were compared with nonthromboembolic pre-capillary pulmonary arterial hypertension cohorts at the participating institutions.

The study population comprised 687 patients assessed at the time of diagnosis between 1996 and 2007. Ventriculo-atrial shunts and infected pacemakers (odds ratio (OR) $76.40,95 \%$ confidence interval (Cl) $7.67-10,351$ ), splenectomy (OR $17.87,95 \%$ Cl $1.56-2,438$ ), previous venous thromboembolism (VTE; OR 4.52, 95\% Cl 2.35-9.12), recurrent VTE (OR $14.49,95 \%$ CI $5.40-43.08)$, blood groups other than $0(2.09,95 \% \mathrm{Cl} 1.12-3.94)$, and lupus anticoagulant/ antiphospholipid antibodies (OR $4.20,95 \% \mathrm{Cl}$ 1.56-12.21) were more often associated with CTEPH. Thyroid replacement therapy (OR 6.10, 95\% $\mathrm{Cl}$ 2.73-15.05) and a history of malignancy (OR $3.76,95 \% \mathrm{Cl} 1.47-10.43$ ) emerged as novel CTEPH risk factors.

In conclusion, the European database study confirmed previous knowledge of chronic thromboembolic pulmonary hypertension risk factors, and identified thyroid replacement therapy and a history of malignancy as new medical conditions associated with chronic thromboembolic pulmonary hypertension.

KEYWORDS: Pulmonary hypertension, risk factors, thromboembolic disease

C hronic thromboembolic pulmonary hypertension $(\mathrm{CTEPH})$ is a serious and underdiagnosed disorder with significant morbidity and mortality. CTEPH is thought to result from single or recurrent pulmonary thromboemboli arising from sites of venous thrombosis [1]. For reasons that are still unclear, the lysis of blood clots does not occur in up to $3.8 \%$ of survivors of acute pulmonary thromboemboli [2], which then evolve into organised obstructions inside the pulmonary artery. Increased vascular resistance results in right heart strain and remodelling. In contrast to venous thromboembolism (VTE), classic plasmatic abnormalities have not been found, with the exception of antiphospholipid antibodies/ lupus anticoagulant (APA/LAC) in 10-20\% of patients [3] and plasma factor VIII (FVIII) $>230 \mathrm{IU} \cdot \mathrm{dL}^{-1}$ in $25 \%$ of patients [4]. Two recent reports have documented an association of splenectomy [5, 6], ventriculo-atrial (VA) shunt for the treatment of hydrocephalus, and chronic inflammatory conditions [5] with CTEPH. The aim of the present study was to confirm known and to detect new associated medical conditions in a large database of patients with CTEPH.

\section{METHODS}

\section{Study design}

The study was a controlled retrospective cohort study that used logistic regression modelling. Three cohorts from four large European pulmonary vascular centres contributed prevalent cases between March 1996 and February 2006 (Vienna, Austria and Bratislava, Slovak Republic), between May 1996 and July 2005 (Homburg, Germany), and between January 2001 and June 2007 (Prague, Czech Republic) into the database. An academic
AFFILIATIONS

*Division of Cardiology,

-Core Unit for Medical Statistics and Informatics,

\#\#Division of Cardiothoracic Surgery, Vienna General Hospital, Medical University of Vienna, Vienna, Austria,

${ }^{\star \star}$ Cardiology Clinic, National Institute of Cardiovascular Diseases, Dept of Cardiology, Slovak Medical University, Bratislava, Slovak Republic, \#Depts of Pneumology, Allergology, and Environmental Medicine,

+Thoracic and Cardiovascular Surgery, University Hospital of Saarland, Homburg/Saar, Germany, §2nd Medical Dept, Clinical Dept of Cardiology and Angiology, and ${ }^{f}$ 2nd Surgical Dept, Clinical Dept of Cardiovascular Surgery, General Teaching Hospital, Prague, Czech Republic.

\section{CORRESPONDENCE}

I.M. Lang, Dept of Internal Medicine II, Division of Cardiology, Medical University of Vienna, Währinger Gürtel 18-20, 1090 Vienna, Austria. Fax: 431404004216 E-mail: irene.lang@meduniwien.ac.at

Received:

June 092008

Accepted after revision:

September 012008

SUPPORT STATEMENT

This study received financial support from the European Commission under the 6th Framework Programme (Contract No: LSHM-CT-2005-018725, PULMOTENSION). This publication reflects only the authors' views and the European Community is in no way liable for any use that may be made of the information contained therein

STATEMENT OF INTEREST None declared 
pulmonary endarterectomy (PEA) programme and yearly follow-up examinations were required for a centre to participate, including the presence of at least one PEA surgeon at the institution. Data from consecutive patients with nonthromboembolic pre-capillary pulmonary arterial hypertension (nonthromboembolic $\mathrm{PH}$ ) were contributed from participating centres to serve as controls. Viennese patient data included patient data previously referred to in other studies [4, 5, 7-9]. The respective ethics committees of the participating institutions approved the study.

\section{Diagnostic criteria}

At all institutions, the diagnoses of CTEPH and nonthromboembolic $\mathrm{PH}$ were established according to the current clinical classification [10], and the indication for surgery was based on published standards [11]. In brief, CTEPH was defined as invasively measured mean pulmonary artery pressure $\geqslant 25 \mathrm{mmHg}$ at rest or unilateral pulmonary artery occlusion in the presence of normal or elevated pressures at rest, a pulmonary wedge pressure $\leqslant 15 \mathrm{mmHg}$, abnormal ventilation/perfusion scan with at least one or more segmental perfusion defect with normal ventilation, an abnormal computed tomography scan and/or abnormal pulmonary angiography showing typical findings of $\mathrm{CTEPH}$, and $\geqslant 3$ months of efficient anticoagulation prior to these assessments.

A history of malignancy, i.e. past or healed cancer, was confirmed by surgical and pathological reports. The diagnosis of inflammatory bowel disease (IBD) was accepted if the clinical, endoscopic, histological and radiological criteria were fulfilled [12]. Evidence for prior VTE was based on clinical symptoms and documented phlebography/ultrasound evidence of deep vein thrombosis, or high probability lung scans at the time of the event. Thyroid hormone substitution therapy was rated only if ongoing at the time of the assessment. All data were extracted from the patients' medical histories at the time of the first diagnostic right heart catheterisation.

The diagnosis of nonthromboembolic PH was based on international criteria [10]. The majority of patients were diagnosed as having Venice class I pulmonary hypertension, i.e. pulmonary arterial hypertension (PAH; table 1).

\section{Statistical analysis}

For the description of the study population, continuous data are presented as mean $\pm \mathrm{SD}$. Because of their skewed distribution, age, body mass index and haemodynamic data are presented as median (interquartile range). Categorical characteristics are described by the number of affected patients. The calculation of percentages ignores missing observations. Exploratory uncorrected p-values from Chi-squared and Mann-Whitney tests for qualitative and continuous data, respectively, were obtained for the factors listed in table 2.

Putative risk factors were investigated for their prognostic relevance by logistic regression. Simple analysis with risk factors adjusted for sex, age and expert centre (marginal effects) was contrasted with multiple analysis using the full model with risk factors adjusted for sex, age, expert centre and all other risk factors, as listed in table 3 (partial effects). Differences between simple and multiple results were investigated by means of Spearman's partial correlation (adjusted for sex, age and expert centre) of the risk factors. Possible departures from main effects models were checked. Starting from a proportion of thyroid (malignancy) patients of $3.5 \%$ $(4.3 \%)$ observed in the control group, the present study would have a power of $88 \%(94 \%)$ to detect a marginal odds ratio (OR) of 3.0 to a significance level of $\alpha=0.05$. The results are presented as ORs and corresponding $95 \%$ confidence intervals (CIs) and p-values.

Because of their small number, patients from Bratislava were added to the Vienna cohort. According to recent data demonstrating staphylococcal DNA in the majority of PEA specimens from VA shunt carriers [7], these subjects were grouped with those with infected pacemakers. Blood group analyses could not be included in the main analysis owing to the unavailability of blood group determinations in Prague in patients who were not scheduled for a surgical procedure. Therefore, the effect of blood group 0 versus all other blood groups was investigated in a separate multiple logistic model excluding patients from Prague, but adjusting for all risk factors.

Because the occurrence of risk factors was low and the ORs were relatively large, the effects were estimated via the penalised likelihood for logistic regression [13]. CIs were obtained by profile penalised likelihood, as implemented in a specialised computer program [14], which gives more reliable results than the standard Wald approach. A p-value $\leqslant 0.05$ was considered to be statistically significant.

\section{RESULTS}

\section{Study population}

A total of 687 consecutive patients with CTEPH $(n=433,63 \%)$ and nonthromboembolic $\mathrm{PH}(\mathrm{n}=254,37 \%)$ were retrospectively studied at the time of their first diagnostic right heart catheterisation. The Medical University of Vienna collected 359 patients, including 9 patients from the Medical University of Bratislava, the Medical University of Prague included 95 patients, and the Medical University of Homburg/Saar contributed 233 patients (table 1).

Details of the study populations are described in table 2. Differences in patient characteristics are in part due to the different referral patterns across the participating centres. While the pulmonary vascular centres in Vienna and Prague are both PEA and general pulmonary hypertension referral centres, the PEA programme and the strength of the pulmonary and intensive care centre are main determinants of the patient population in Homburg.

The median age of CTEPH patients (58.0 yrs) was, on average, higher than that of nonthromboembolic $\mathrm{PH}$ patients $(50.5 \mathrm{yrs}$; fig. 1). There were $52 \%$ females in the CTEPH and $66 \%$ in the nonthromboembolic PH diagnostic category. On average, diagnoses were established 2 yrs after the first symptoms (usually unexplained dyspnoea on exertion). The distribution of functional classes was similar in CTEPH and nonthromboembolic $\mathrm{PH}$ at the time of diagnosis, with the majority of patients presenting in class III/IV (83\% of CTEPH patients versus $78 \%$ of nonthromboembolic $\mathrm{PH}$ patients). In the majority of patients, 6-min walking distances were assessed but could not be reported, as there were too many missing values in the years 1996-1999. Although surgery was offered at each 


\section{TABLE 1 Diagnoses by participating centres}

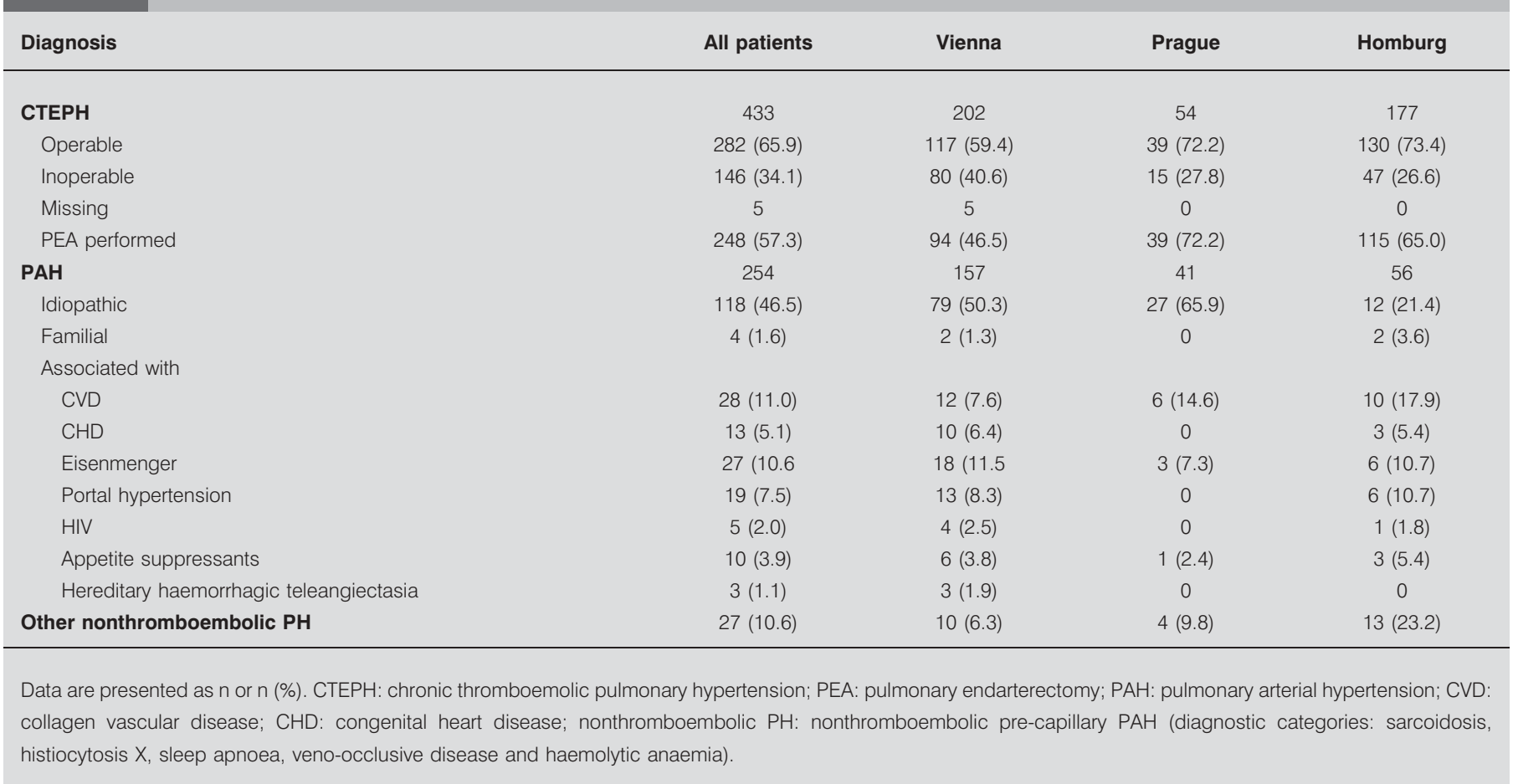

participating centre, the rate of PEA varied between $47 \%$ (Vienna), 65\% (Homburg) and 72\% (Prague; table 1).

Clinical histories were suggestive of a thromboembolic origin of CTEPH. While almost $70 \%$ of patients with CTEPH had a history of VTE, this was reported in only $11 \%$ of patients with nonthromboembolic PH. Recurrent VTE was frequent in the CTEPH group $(n=225,52.2 \%)$, and a rare finding in the nonthromboembolic $\mathrm{PH}$ group $(n=6,3.2 \%)$. Previous leg trauma occurred in nine CTEPH patients, and in none of the nonthromboembolic PH patients. There were 13 cases of arm vein thromboses in the CTEPH group, and one in the nonthromboembolic $\mathrm{PH}$ group.

Not a single patient with CTEPH suffered from systemic lupus erythematosus. Abnormal haemoglobins, osteomyelofibrosis and COPD occurred in $2.1 \%, 1.2 \%$ and $1.5 \%$ of CTEPH patients, respectively. A history of malignant disease was more frequently observed in CTEPH (12.2 versus 4.7\%), mainly breast cancer, gastrointestinal carcinoma, melanoma, prostate cancer and seminoma. The time interval between the diagnosis of cancer and CTEPH was in the order of 5-10 yrs.

While pacemakers in general were equally frequent in both diagnosis groups $(1.4 \%$ in $\mathrm{CTEPH}, 1.2 \%$ in nonthromboembolic $\mathrm{PH})$, pacemakers with a history of infection were observed in four CTEPH patients, but in none of the patients with nonthromboembolic PH.

\section{Risk factors for CTEPH}

Putative risk factors were selected according to current knowledge on CTEPH to enter the logistic regression model. Results from logistic regression analysis apply to 585 patients with complete data sets.
Splenectomy, and VA shunt and/or infected pacemakers were confirmed as risk factors for CTEPH in the multiple analysis (table 3). IBD did not reach statistical significance in this multicentre observation, although 12 patients were affected in the CTEPH group, compared with only three in the nonthromboembolic $\mathrm{PH}$ group. As expected, previous and recurrent VTE were strongly associated with CTEPH. Chronic venous ulcers were shown to be more prevalent in the CTEPH diagnosis group, and borderline significant in the multiple analysis. Ongoing thyroid replacement therapy was strongly associated with the diagnosis of CTEPH.

Differences between results of simple and multiple analyses can be explained by correlations. Previous and recurrent VTE were positively correlated $(\mathrm{r}=0.75)$, as were abnormal haemoglobins and splenectomy $(\mathrm{r}=0.50)$. The absolute value of the other correlation coefficients was below 0.30. No interactions (effect modifications) of the putative risk factors were assessed due to insignificance.

When blood groups were analysed, data from Prague had to be excluded because there were no entries from this centre in the nonthromboembolic PH group. In 495 patients, after adjustment for all other variables in the model, the binary variable blood group not 0 was a predictor for the diagnosis of CTEPH (OR 2.09, 95\% CI 1.12-3.94; $\mathrm{p}=0.019$ ).

\section{DISCUSSION}

The present registry of patients represents the largest contemporary population with $\mathrm{CTEPH}$, including operable and inoperable cases, thus providing an updated description of this orphan disease in the Western world. Previously, large patient series have been derived from medical [15-17] and surgical databases $[18,19]$, with the most recent representing 
TABLE 2 Clinical and haemodynamic data by diagnosis

\begin{tabular}{|c|c|c|}
\hline & $\begin{array}{c}\text { Thromboembolic } \\
\text { PH }\end{array}$ & $\begin{array}{c}\text { Nonthromboembolic } \\
\text { PH }\end{array}$ \\
\hline Subjects & 433 & 254 \\
\hline Female patients* & $227(52.4)$ & $167(65.8)$ \\
\hline \multicolumn{3}{|l|}{ 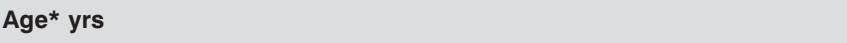 } \\
\hline Median (range) & $58(46-67)$ & $50.5(37-64)$ \\
\hline Missing & 2 & 4 \\
\hline \multicolumn{3}{|l|}{ Height* cm } \\
\hline Mean \pm SD & $170.2 \pm 9.1$ & $166.6 \pm 9.2$ \\
\hline Missing & 72 & 25 \\
\hline \multicolumn{3}{|l|}{ Weight* kg } \\
\hline Mean \pm SD & $76.3 \pm 14.8$ & $72.3 \pm 17.3$ \\
\hline Missing & 72 & 23 \\
\hline \multicolumn{3}{|l|}{ Body surface area* $m^{2}$} \\
\hline Mean $\pm S D$ & $1.89 \pm 0.21$ & $1.81 \pm 0.24$ \\
\hline Missing & 74 & 26 \\
\hline \multicolumn{3}{|l|}{$B M I \mathbf{k g} \cdot \mathbf{m}^{-2}$} \\
\hline Median (range) & $26.0(23.4-28.5)$ & $25.2(22.5-29.0)$ \\
\hline Missing & 72 & 25 \\
\hline \multicolumn{3}{|l|}{ WHO class ${ }^{\#} \mathrm{I} / \mathrm{II} / \mathrm{III} / \mathrm{IV}$} \\
\hline Subjects & 6/66/215/132 & 4/33/99/29 \\
\hline Subjects \% & $1.4 / 15.8 / 51.3 / 31.5$ & 2.4/20.0/60.0/17.6 \\
\hline Missing & 14 & 89 \\
\hline \multicolumn{3}{|l|}{ Time to diagnosis months } \\
\hline Median (interquartile range) & $24(12-48)$ & $24(11-56)$ \\
\hline Missing & 170 & 163 \\
\hline \multicolumn{3}{|l|}{ Haemodynamic data } \\
\hline \multicolumn{3}{|l|}{ MVS* \% } \\
\hline Median (range) & $59.0(52.0-64.0)$ & $66.2(59.6-71.6)$ \\
\hline Missing & 112 & 81 \\
\hline \multicolumn{3}{|l|}{$\bar{P} \mathrm{pa}^{\star} \mathrm{mmHg}$} \\
\hline Median (range) & $50(41-57)$ & $69(50-94)$ \\
\hline Missing & 70 & 89 \\
\hline \multicolumn{3}{|l|}{$C O^{*} L \cdot m^{-1}$} \\
\hline Median (range) & $3.8(3.2-4.5)$ & $4.1(3.3-5.2)$ \\
\hline Missing & 55 & 67 \\
\hline \multicolumn{3}{|l|}{ PVR dyn $\cdot s \cdot \mathrm{cm}^{-5}$} \\
\hline Median (range) & $830(574-1128)$ & $786(531-1198)$ \\
\hline Missing & 18 & 59 \\
\hline \multicolumn{3}{|l|}{ Risk factors } \\
\hline \multicolumn{3}{|l|}{ Previous VTE* } \\
\hline Subjects & $280(69.0)$ & $20(10.6)$ \\
\hline Missing & 27 & 65 \\
\hline \multicolumn{3}{|l|}{ Recurrent VTE* } \\
\hline Subjects & 225 (52.2) & $6(3.2)$ \\
\hline Missing & 2 & 64 \\
\hline Malignancy* & $53(12.2)$ & $11(4.3)$ \\
\hline Breast cancer & 12 & 1 \\
\hline Gl carcinoma & 9 & 1 \\
\hline Melanoma & 3 & 0 \\
\hline Prostate cancer & 2 & 3 \\
\hline Sarcoma & 2 & 1 \\
\hline Bronchial carcinoma & 3 & 2 \\
\hline Hepatocellular carcinoma & 0 & 1 \\
\hline Chronic myeloid leukaemia & 1 & 1 \\
\hline Renal cell carcinoma & 2 & 1 \\
\hline Uterus carcinoma & 3 & 0 \\
\hline
\end{tabular}

Thromboembolic Nonthromboembolic $\mathrm{PH}$ PH

\begin{tabular}{|c|c|c|}
\hline Ovarian cancer & 1 & 0 \\
\hline Seminoma & 3 & 0 \\
\hline Thymoma & 1 & 0 \\
\hline Astrocytoma & 1 & 0 \\
\hline Plasmocytoma & 2 & 1 \\
\hline Other malignancies & 8 & 0 \\
\hline Thyroid hormone replacement* & 86 (19.9) & $9(3.5)$ \\
\hline Ventriculo-atrial shunt* & $12(2.8)$ & 0 \\
\hline Pacemaker & $6(1.4)$ & $3(1.2)$ \\
\hline Infected pacemaker & $4(0.9)$ & 0 \\
\hline \multicolumn{3}{|l|}{ Splenectomy* } \\
\hline Subjects & $24(5.5)$ & 0 \\
\hline Missing & 0 & $4(3.3)$ \\
\hline Previous leg trauma* & $9(2.1)$ & 0 \\
\hline Inflammatory bowel disease & $12(2.8)$ & $3(1.2)$ \\
\hline Chronic venous ulcers* & $47(10.9)$ & $6(2.4)$ \\
\hline \multicolumn{3}{|l|}{ APA/LAC* } \\
\hline Subjects & $43(10.0)$ & $10(4.0)$ \\
\hline Missing & $2(0.5)$ & $1(0.4)$ \\
\hline \multicolumn{3}{|l|}{ Systemic lupus erythematosus* } \\
\hline Subjects & 0 & $8(3.2)$ \\
\hline Missing & $1(0.2)$ & 0 \\
\hline Arm vein thrombosis* & $13(3.0)$ & $1(0.4)$ \\
\hline Coronary artery disease & $10(2.3)$ & $1(0.4)$ \\
\hline Haemoglobin abnormalities* & $9(2.1)$ & 0 \\
\hline Osteomyelofibrosis & $5(1.2)$ & $1(0.4)$ \\
\hline Klippel-Trenaunay syndrome & $2(0.5)$ & 0 \\
\hline Klinefelter syndrome & 0 & 0 \\
\hline \multicolumn{3}{|l|}{ Ischaemic stroke } \\
\hline Subjects & $19(4.4)$ & $12(4.7)$ \\
\hline Missing & $3(0.7)$ & 0 \\
\hline COPD & $8(1.8)$ & $8(3.2)$ \\
\hline Sarcoidosis & $2(0.5)$ & $4(1.6)$ \\
\hline
\end{tabular}

Data are presented as $\mathrm{n}$ or $\mathrm{n}(\%)$, unless otherwise stated. $\mathrm{PH}$ : pulmonary hypertension; BMI: body mass index; WHO: World Health Organization; MVS: mixed venous saturation; $\bar{P}$ pa: mean pulmonary artery pressure; $\mathrm{CO}$ : cardiac output; PVR: pulmonary vascular resistance; VTE: venous thromboembolism; Gl: gastrointestinal; APA/LAC: antiphospholipid antibodies/lupus anticoagulant; COPD: chronic obstructive pulmonary disease. *: $p<0.05$; * : $p<0.05$ for WHO class I/II versus III/IV. ": at the time of diagnosis.

an in-depth analysis of 1,500 consecutive patients [20]. In the past 20 years it has become recognised that several conditions and diseases could be associated with classical pre-capillary PAH [21-23]. Similarly, recent series of $181[5,9]$ and 257 patients [6] diagnosed with CTEPH have identified distinct medical conditions (associated medical conditions) linked to the development of CTEPH. These include splenectomy [5, 6], VA shunt for the treatment of hydrocephalus, as well as other permanent central intravenous lines, IBD and osteomyelitis [9].

The present investigation aimed to confirm known and to detect new associated medical conditions in a large database of patients with CTEPH. Overall, CTEPH patients tended to be older and tended to have more comorbidities than nonthromboembolic $\mathrm{PH}$ patients. The key findings were that previously 
TABLE 3 Crude and adjusted odds ratios (ORs) for the risk of chronic thromboembolic pulmonary hypertension

\begin{tabular}{|c|c|c|c|c|}
\hline Condition & OR $(95 \% \mathrm{Cl})$ & $\mathrm{p}$-value & OR $(95 \% \mathrm{Cl})$ & p-value \\
\hline Thyroid hormone replacement & $5.41(2.70-12.23)$ & $<0.001$ & $6.10(2.73-15.05)$ & $<0.001$ \\
\hline Malignancy & $1.99(1.01-4.26)$ & 0.046 & $3.76(1.47-10.43)$ & 0.005 \\
\hline Previous VTE & $19.36(11.66-33.79)$ & $<0.001$ & $4.52(2.35-9.12)$ & $<0.001$ \\
\hline APA/LAC & $3.28(1.58-7.50)$ & 0.001 & $4.20(1.56-12.21)$ & 0.004 \\
\hline Systemic lupus erythematosus & $0.06(0.00-0.48)$ & 0.005 & $0.11(0.00-1.21)$ & 0.076 \\
\hline VA shunt or infected pacemaker & $19.49(2.47-2520.10)$ & 0.001 & $76.40(7.67-10350.62)$ & $<0.001$ \\
\hline Inflammatory bowel disease & $2.21(0.69-9.05)$ & 0.189 & $3.19(0.74-16.03)$ & 0.121 \\
\hline Splenectomy & 22.09 (2.97-2824.53) & $<0.001$ & $17.87(1.56-2438.07)$ & 0.017 \\
\hline Abnormal haemoglobins & $7.97(0.98-1035.53)$ & 0.054 & $0.84(0.05-122.42)$ & 0.916 \\
\hline
\end{tabular}

reported associated medical conditions were largely confirmed, including information on the prevalence of APA/LAC [3], and the association with splenectomy, VA shunt [5], and blood group other than 0 [4]. Prevalences were similar regardless of whether patients with PAH [6] or patients with acute VTE not developing CTEPH [5] were regarded as controls. By contrast, IBD and osteomyelitis were not found to be more prevalent in patients with CTEPH. Previous and recurrent VTE, chronic venous ulcers, thyroid hormone replacement therapy and malignancy were associated with CTEPH in 433 patients from several European centres. The greater than commonly reported rate of previous VTE $[1,24]$ in $69 \%$ of patients with CTEPH may have resulted from the increased awareness of thrombosis in the participating PEA expert centres.

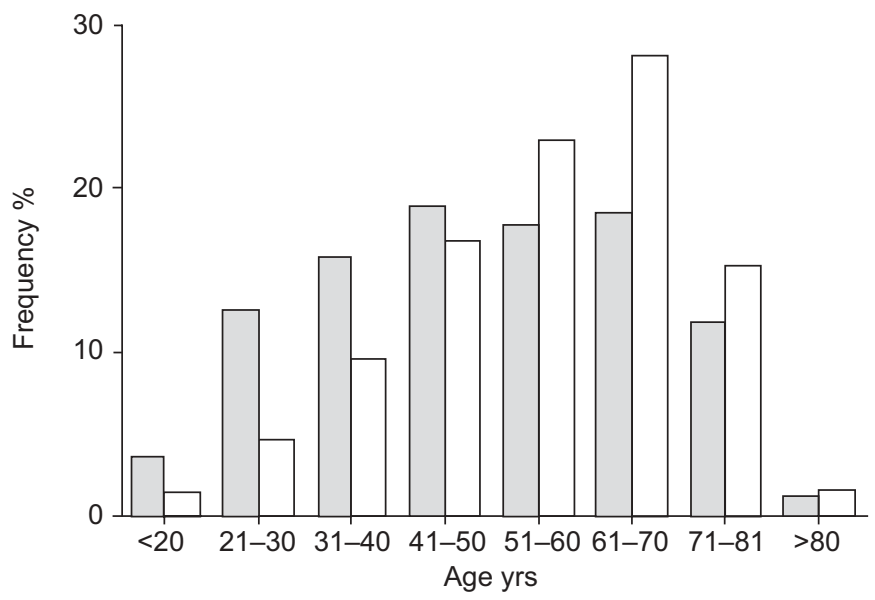

FIGURE 1. Age distribution of patients diagnosed with chronic thromboembolic pulmonary hypertension (CTEPH) and nonthromboembolic pre-capillary pulmonary arterial hypertension (PAH). PAH and other diagnoses were summarised as "PAH" according to the Venice classification [10]. $\square: \mathrm{PAH} ; \square: \mathrm{CTEPH}$.

\section{Thyroid disease}

The prevalence of subclinical hypothyroidism is $4-8 \%$ in the general population, and up to $15-18 \%$ in females who are aged $>60$ yrs [25]. For comparison, the prevalence of recognised thyroid disease (either self-reported history of thyroid disease or current levothyroxin treatment) in a population aged $>49$ yrs was reported to be $10 \%$ [26]. Therefore, the observation of $\sim 20 \%$ of patients with CTEPH under thyroid hormone replacement is not only statistically different from the nonthromboembolic PH comparator, but appears biologically meaningful. These data are in contradiction to recent work demonstrating a $24 \%$ prevalence of thyroid disorders in patients with nonthromboembolic $\mathrm{PH}$ in a 356-patient observation [27]. However, while a broad spectrum of serologic thyroid alterations was studied, with only $50-70 \%$ of patients having invasively confirmed $\mathrm{PH}$ [27], the present data collection was confined to medical thyroid replacement therapy that was ongoing at the time of diagnosis. Based on the available data it cannot be said whether the risk of developing CTEPH can be attributed to hypothyroidism or thyroid hormone replacement therapy, or both.

It has been shown that patients suffering from moderate hypothyroidism are at an increased risk of thrombosis [28]. In addition, treatment with levothyroxin increases von Willebrand factor (vWF) levels and shortens in vitro platelet plug formation measured as collagen-epinephrine-induced closure time [29]. The current authors have previously shown that CTEPH patients had higher FVIII/vWF levels than healthy subjects and PAH patients [4]. One year after PEA these levels were unchanged suggesting a role of elevated FVIII/vWF in disease pathogenesis [4]. In accordance with knowledge on genetic factors determining the variation in plasma concentration of FVIII/vWF [30], blood groups other than 0 were more prevalent in CTEPH patients [4], a finding that was confirmed in the registry. 


\section{Cancer}

Epidemiological studies have identified malignancy as an independent thrombosis risk factor and show that cancer patients are at increased risk of both initial and recurrent venous thromboembolic events. In cancer patients, the effects of chemotherapy and other treatments compound this risk. The interaction of tissue factor, thrombin and other coagulation factors with protease-activated receptor proteins expressed by tumour cells and host vascular cells leads to the induction of genes related to angiogenesis, cell survival and cell adhesion and migration [31]. The findings of the registry support the concept that malignancy is associated with CTEPH. Although there are several kinds of malignancies that have been found to be associated with VTE [32], CTEPH-associated cancers appear to have been survived several years prior to the diagnosis of CTEPH. Whether treatment-related factors, e.g. adjuvant hormone replacement therapies, are also contributory cannot be clarified from the present study. Yet, based on the results, pulmonary hypertension in a tumour survivor should be a signal to search for CTEPH, rather than for another aetiology of pulmonary hypertension.

\section{Study limitations}

The present retrospective study design may favour the inclusion of survivors. The sensitivity analysis (regression diagnostics as previously described [33]) showed that the estimates for the covariate effects are stable, with exception of the OR for splenectomy, which is highly dependent on a few observations and may be as low as half of its value reported in table 3. Furthermore, no follow-ups were obtained in the current investigation, and medical treatments were not monitored. While there exists a referral bias based on the fact that the participating university hospitals represent PEA centres, diagnoses were made according to international guidelines. The reported ORs do not truly describe the risk of CTEPH in patients with a particular medical condition, but the OR of having the medical condition when compared to nonthromboembolic $\mathrm{PH}$ patients. Future prospective CTEPH databases are required to gain a full overview of this disorder.

\section{Conclusion}

The findings of the present study underscore previous work on the thromboembolic nature of chronic thromboembolic pulmonary hypertension [2] by confirming an association with previous and recurrent venous thromboembolism, antiphospholipid antibodies/lupus anticoagulant and blood groups other than 0 . However, recent research has provided evidence suggesting that the mechanistic view of chronic thromboembolic pulmonary hypertension as a disease caused by obliteration of central pulmonary arteries due to a classic thrombotic process may have been too simplistic [24, 34]. The current authors speculate that pulmonary embolism may be followed by a pulmonary vascular remodelling process that is modified by infection [7], immune phenomena [3] and, possibly, by thyroid hormone replacement therapy and malignancy.

\section{REFERENCES}

1 Lang IM. Chronic thromboembolic pulmonary hypertension-not so rare after all. N Engl J Med 2004; 350: 2236-2238.
2 Pengo V, Lensing AW, Prins MH, et al. Incidence of chronic thromboembolic pulmonary hypertension after pulmonary embolism. N Engl J Med 2004; 350: 2257-2264.

3 Wolf M, Boyer-Neumann C, Parent F, et al. Thrombotic risk factors in pulmonary hypertension. Eur Respir J 2000; 15: 395-399.

4 Bonderman D, Turecek PL, Jakowitsch J, et al. High prevalence of elevated clotting factor VIII in chronic thromboembolic pulmonary hypertension. Thromb Haemost 2003; 90: 372-376.

5 Bonderman D, Jakowitsch J, Adlbrecht C, et al. Medical conditions increasing the risk of chronic thromboembolic pulmonary hypertension. Thromb Haemost 2005; 93: 512-516.

6 Jais X, Ioos V, Jardim C, et al. Splenectomy and chronic thromboembolic pulmonary hypertension. Thorax 2005; 60: 1031-1034.

7 Bonderman D, Jakowitsch J, Redwan B, et al. Role for Staphylococci in misguided thrombus resolution of chronic thromboembolic pulmonary hypertension. Arterioscler Thromb Vasc Biol 2008; 28: 678-684.

8 Bonderman D, Nowotny R, Skoro-Sajer N, et al. Bosentan therapy for inoperable chronic thromboembolic pulmonary hypertension. Chest 2005; 128: 2599-2603.

9 Bonderman D, Skoro-Sajer N, Jakowitsch J, et al. Predictors of outcome in chronic thromboembolic pulmonary hypertension. Circulation 2007; 115: 2153-2158.

10 Galie N, Torbicki A, Barst R, et al. Guidelines on diagnosis and treatment of pulmonary arterial hypertension. The Task Force on Diagnosis and Treatment of Pulmonary Arterial Hypertension of the European Society of Cardiology. Eur Heart J 2004; 25: 2243-2278.

11 Klepetko W, Mayer E, Sandoval J, et al. Interventional and surgical modalities of treatment for pulmonary arterial hypertension. J Am Coll Cardiol 2004;43, 12: Suppl. S, 73S-80S.

12 Lennard-Jones JE, Shivananda S. Clinical uniformity of inflammatory bowel disease a presentation and during the first year of disease in the north and south of Europe. EC-IBD Study Group. Eur J Gastroenterol Hepatol 1997; 9: 353-359.

13 Heinze G, Schemper M. A solution to the problem of separation in logistic regression. Stat Med 2002; 21: 2409-2419.

14 Heinze G, Ploner M. Fixing the nonconvergence bug in logistic regression with SPLUS and SAS. Comput Methods Programs Biomed 2003; 71: 181-187.

15 Kunieda T, Nakanishi N, Satoh T, Kyotani S, Okano Y, Nagaya N. Prognoses of primary pulmonary hypertension and chronic majorvessel thromboembolic pulmonary hypertension determined from cumulative survival curves. Intern Med 1999; 38: 543-546.

16 Lewczuk J, Piszko P, Jagas J, et al. Prognostic factors in medically treated patients with chronic pulmonary embolism. Chest 2001; 119: 818-823.

17 Riedel M, Stanek V, Widimsky J, Prerovsky I. Longterm follow-up of patients with pulmonary thromboembolism. Late prognosis and evolution of hemodynamic and respiratory data. Chest 1982; 81: 151-158.

18 Blauwet LA, Edwards WD, Tazelaar HD, McGregor CG. Surgical pathology of pulmonary thromboendarterectomy: a study of 54 cases from 1990 to 2001. Hum Pathol 2003; 34: 1290-1298.

19 Dartevelle P, Fadel E, Mussot S, et al. Chronic thromboembolic pulmonary hypertension. Eur Respir J 2004; 23: 637-648. 
20 Jamieson SW, Kapelanski DP, Sakakibara N, et al. Pulmonary endarterectomy: experience and lessons learned in 1,500 cases. Ann Thorac Surg 2003; 76: 1457-1462.

21 D'Alonzo GE, Barst RJ, Ayres SM, et al. Survival in patients with primary pulmonary hypertension. Results from a national prospective registry. Ann Intern Med 1991; 115: 343-349.

22 Rich S, Dantzker DR, Ayres SM, et al. Primary pulmonary hypertension. A national prospective study. Ann Intern Med 1987; 107: 216-223.

23 Simonneau G, Galie N, Rubin LJ, et al. Clinical classification of pulmonary hypertension. J Am Coll Cardiol 2004;43, 12: Suppl. S, 5S-12S.

24 Hoeper MM, Mayer E, Simonneau G, Rubin LJ. Chronic thromboembolic pulmonary hypertension. Circulation 2006; 113: 2011-2020.

25 Villar HC, Saconato H, Valente O, Atallah AN. Thyroid hormone replacement for subclinical hypothyroidism. Cochrane Database Syst Rev 2007; 3: CD003419.

26 Empson M, Flood V, Ma G, Eastman CJ, Mitchell P. Prevalence of thyroid disease in an older Australian population. Intern Med J 2007; 37: 448-455.
27 Li JH, Safford RE, Aduen JF, Heckman MG, Crook JE, Burger CD. Pulmonary hypertension and thyroid disease. Chest 2007; 132: 793-797.

28 Franchini M. Hemostatic changes in thyroid diseases: haemostasis and thrombosis. Hematology 2006; 11: 203-208.

29 Homoncik M, Gessl A, Ferlitsch A, Jilma B, Vierhapper H. Altered platelet plug formation in hyperthyroidism and hypothyroidism. J Clin Endocrinol Metab 2007; 92: 3006-3012.

30 Orstavik KH, Magnus P, Reisner H, Berg K, Graham JB, Nance W. Factor VIII and factor IX in a twin population. Evidence for a major effect of ABO locus on factor VIII level. Am J Hum Genet 1985; 37: 89-101.

31 Bick RL. Cancer-associated thrombosis. N Engl J Med 2003; 349: 109-111.

32 Semrad TJ, O'Donnell R, Wun T, et al. Epidemiology of venous thromboembolism in 9489 patients with malignant glioma. J Neurosurg 2007; 106: 601-608.

33 Hosmer DW, Lemeshow S. Applied logistic regression. 2nd Edn. New York, Wiley, 2000.

34 Egermayer $\mathrm{P}$, Peacock AJ. Is pulmonary embolism a common cause of chronic pulmonary hypertension? Limitations of the embolic hypothesis. Eur Respir J 2000; 15: 440-448. 